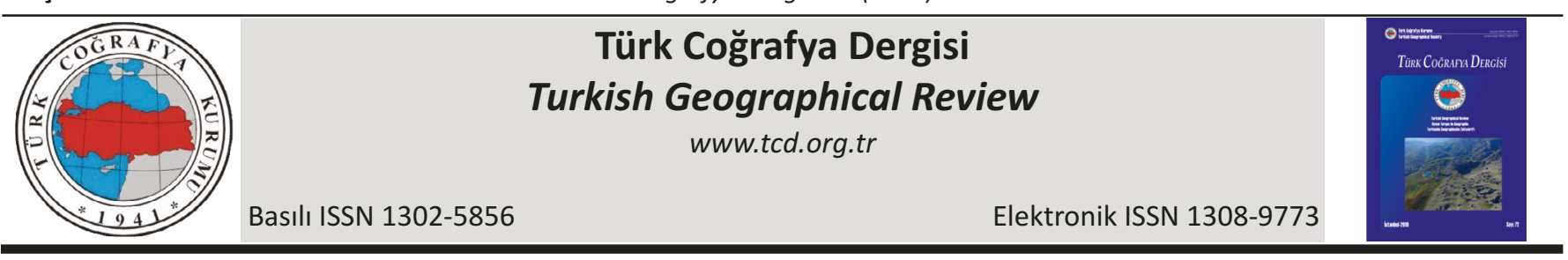

\title{
Antep savunması'nın Gaziantep ili yerleşme adları üzerindeki etkisi ve bu etkinin Coğrafi Bilgi Sistemleri tabanlı mekânsal analizi
}

\author{
The effect of Antep defence on the settlement names in Gaziantep and Geographic Information \\ System-based spatial analysis of this effect
}

\author{
Erol Uzun*a (i) Pınar Doğan Uzun ${ }^{b}$ (1) \\ ${ }^{a}$ Bursa Uludağ Üniversitesi, Fen-Edebiyat Fakültesi, Coğrafya Bölümü, Bursa. \\ ${ }^{b}$ Kahramanmaraş Sütçü İmam Üniversitesi, Sosyal Bilimler Enstitüsü, Kahramanmaraş.
}

\section{BILGI / INFO}

Geliş/Received: 07.12.2018

Kabul/Accepted: 25.01.2019

Anahtar Kelimeler:

Gaziantep

Antep Savunması

Yerleşme adları

\section{Keywords:}

Gaziantep

The defence of Antep

Settlement names

*Sorumlu yazar/Corresponding author:

(E. Uzun) eroluzun@uludag.edu.tr

DOI: $10.17211 /$ tcd. 493224

\section{Atff/Citation:}

Uzun, E. ve Uzun, P. D. (2019). Antep Savunması'nın Gaziantep ili Yerleşme Adları Üzerindeki Etkisi ve Bu Etkinin Coğrafi Bilgi Sistemleri Tabanlı Mekânsal Analizi. Türk Coğrafya Dergisi (72), 7-12. DOI:10.17211/tcd.493224.

\begin{abstract}
ÖZ / ABSTRACT
Antep Savunması süresince 6317 şehit verilmesi ve zor şartlar altında bir yılı aşkın bir süre boyunca Fransızlara karşı büyük bir direniş gösterilmiş olması nedeniyle TBMM tarafindan 6 Şubat 1921'de şehre "Gazilik" unvanı verilerek Antep halkının onurlandırılması, eski Türk devletlerindeki ad verme geleneğiyle benzerlik göstermektedir. Günümüz şartları açısından bakıldığında ise, gazilik unvanı ile mekâna kutsallık kazandırıması ve halkın onurlandırılması, ulus ve ulus devlet inşa etme amacına yönelikti. Ancak vatanın yeniden inşası sürecinde yerleşme adlarında görülen değişimi sadece Türklere ve Türk devletlerine özgü bir durum olarak algılamak doğru değildir. Bağımsızlığı yeni elde etmiş veya elde etme mücadelesi veren uluslar, genellikle benzer uygulamalara başvurmakta ve bölgeye hâkim olduklarını göstermek amacıyla yer ve yerleşme adlarını kendilerine uygun hale getirme çabası içerisine girmektedirler. Antep Savunması'nın yerleşme adları üzerindeki etkisinin ve Coğrafi Bilgi Sistemleri'nden yararlanılarak bu etkinin mekân üzerindeki yansımasının ele alındığı çalışmada, yerleşme adları-olay-mekân ilişkisi analiz edilmeye çalışılmıştır. Coğrafi Bilgi Sistemlerinin, mekân üzerinde yapılacak araştırmalara yeni yaklaşımlar kazandırması, son yıllarda yerleşme adları konusunda yürütülen araştırmalarda görülen artışa rağmen coğrafyacılar tarafindan yapılan araştırmaların sayıca azlığı ve Antep Savunması'nın yerleşme adları üzerindeki güçlü etkisi, çalışmanın yapılmasındaki gerekçeleri oluşturmaktadır. İlin ve iki merkez ilçenin, şehrin, il merkezindeki mahalle yerleşmelerinin yaklaşık \% 3’nün ve sokak sayısının \% 0,25'inin adı üzerinde Antep Savunması'nın etkisinin görülmesi, bu güçlü etkinin somut kanıtlarını oluşturmaktadır.
\end{abstract}

Naming a person has an important place among the Turks' old traditions. As mentioned in the Turkish epics and legends, the young would not be accepted as the member of the clan until they showed acts of heroism and also they would not be called by other names except for their given name by their fathers. Because 6317 people were martyred and they showed resistance to the French for nearly a year under difficult conditions during the defence of Antep, the city was given the title "Ghazi" by The Grand National Assembly of Turkey on 6, February, 1921 and thus the citizens of Antep were honoured, which shows similarity to the mentioned traditions of naming. Considering today's conditions, bringing holiness to the place with the honorary title for war veterans (Ghazi) and honouring the public were realized for the purpose of establishing a nation and nation-state. However, it is not correct to perceive this change experienced with the settlement names during the re-establishment of the nation as a condition unique to the Turks and Turkic countries. The nations that have gained their independence or have been fighting for their independence usually apply similar practices and they make an effort to adjust the names of the places and settlements suitable to themselves to show that they dominate the region. This study which discusses the effects of the Antep Defence on the settlement names and the reflections of this effect on the space via benefiting from Geographical Information System tried to analyse the relationship between the settlement names-events-space. Acquiring new approaches for the research studies carried out about the space via geographical information systems, the scarcity of the number of the studies carried out by the geographers despite the increasing number of the research studies carried out about the settlement names in recent years and the strong influence of the Antep Defence on the settlement names constitute the rationales for the research to be carried out. The fact that the effect of the Antep Defence on the names of the city and the two central districts, nearly $3 \%$ of the neighbourhoods of the city and $0,25 \%$ of the total number of the streets constitute the concrete evidence of this strong influence. 


\section{Giriş}

Insanlar; konumlandırmak, tanımlamak veya etiketlemek amacıyla mekânları adlandırma gereksinimi duyarlar (Conedera, vd, 2007). Mekânın adlandırıması; ülkelerin tarihi, siyasi amaçları, kültürü, kişi adları, arazi kullanımı, bitki örtüsü ve hayvan türleri, hidrografik ve topografik özellikleri, mülkiyet durumu, fiziki ve sosyal çevrenin diğer özellikleriyle bağlantılı olarak şekillenmektedir (Conedera, vd, 2007; Khvesko, 2014; Tunçel, 2000). Örneğin araştırma sahasını oluşturan Gaziantep'e bakıldığında; Şahinbey, Şehitkâmil, 25 Aralık, Kurtuluş, Beydili, Barak, Hoşgör, Boyacı, Tabakhane, Perilikaya, Türktepe, Düztepe, Kolejtepe, Çukur, Karataş, Karatarla, Mağarabaşı, Suburcu, Balıklı, Kargasekmez, Kavaklık, Zeytinli gibi farklı beşeri ve fiziki unsurları yansıtan mekân adlarına rastlanılmaktadır (Işıkhan, 2008; Sönmez, 2012). Bu nedenle Alagöz (1984), yer adlarını geniş bir konu olarak tanımlamıştır.

Mekân, Türklerin anlayış ve yaşamındaki önemli kavramlardan biridir (Ayanovna, 2014). Nitekim mekân, uğrunda ölünecek değer olarak vatan kavramı adı altında kutsallaştırılmıştır. Türklerde mekân anlayışının yaşamlarında önemli yer tutması, mekân isimlerini de önemli kılmıştı. Yer ve yerleşme adları, mekânın yani vatanın inşa süreci olarak görülmüştür. Bu nedenle, Türkçe olmayan yer ve yerleşme adları, ülkenin toprak bütünlüğünü tehdit eden bir unsur olarak algılanmıştir (Durgun, 2018). Türkiye'de yapılan yer ve yerleşme adlarının Türkçeleştirilmesi çalışmaları belirtilen duruma örnek teşkil etmektedir. Cumhuriyetin ilanından sonra ulus devletin inşa süreci içerisinde, birçok alanda olduğu gibi, yer ve yerleşme adlarında da değişim yaşanmıştır. T.C. İçişleri Bakanlığı tarafindan hazırlanan "Yeni Tabii Yer Adları 1977" adlı eserde "Türkçe olmayan yerleşme yerleri ile tabii yer adlarının Türkçeleştirilmesi, milli varlığımızla yakından ilgili görülerek 1940 yılında çalışmalara başlanmış ..." ifadesiyle, planlanan değişimin amacı ve gerekçesi belirtilmiştir. Aynı eserde "Ad değiştirme çalışmalarında bütün ağırlığın yerleşme yerleri ile bağlılarına verilmesi ..." ifadesiyle de çalışmanın asıl odak noktası açıklanmıştır. Türkçeleştirilme faaliyetinin İçişleri Bakanlığı'nda bir kurul eliyle yürütülmesi ise, çalışmanın milli kaygılar ve amaçlarla gerçekleştirildiğini göstermektedir.

Türklerin eski gelenekleri arasında önemli yere sahip olan bir diğer konu kişiye ad vermedir. Türklerin destan ve masallarında da belirtildiği üzere, gençler, kahramanlık gösterinceye kadar boyun üyesi olarak kabul görmez ve babasının verdiği isimden başka ad taşıyamazlardı. Örneğin Dede Korkut Hikâyelerine göre, savaşta kahramanlık veya avda yararlılık gösterenlere boyun bütün bireyleri toplanarak ad verirlerdi (Inan, 1976). Antep Savunması süresince 6317 şehit verilmesi ve zor şartlar altında bir yılı aşkın bir süre boyunca Fransızlara karşı büyük bir direniş gösterilmiş olması nedeniyle TBMM tarafindan 6 Şubat 1921 'de şehre "Gazilik" unvanı verilerek Antep halkının onurlandırılması, belirtilen ad verme geleneğiyle benzerlik göstermektedir (Uzun, 2014). Türkiye Cumhuriyeti Devleti'nin kuruluş şartları açısından bakıldığında, Gazilik unvanı ile mekâna kutsallık kazandırıması ve halkın onurlandırılması, ulus ve ulus devlet inşa etme amacına yönelikti. Ancak vatanın yeniden inşası sürecinde yerleşme adlarında görülen değişimi sadece Türklere ve Türk devletlerine özgü bir durum olarak algılamak doğru değildir. Bağımsızlığı yeni elde etmiş veya elde etme mü- cadelesi veren uluslar, ulus ve ulus devlet inşa süreci içerisinde benzer uygulamalara başvurmakta ve "sınırları kontrol eden gücü yerleşme adlarına yansıtarak ülke veya bölgedeki kontrolü sürdürdüklerini" (Giraut ve Holzschuch, 2016) gösterme çabası içerisine girmektedirler.

\section{Veri ve Yöntem}

Coğrafi Bilgi Sistemlerinin mekân üzerinde yapılacak araştırmalara yeni yaklaşımlar kazandırması, son yıllarda yerleşme adları konusunda yürütülen araştirmalarda görülen artı̧a rağmen coğrafyacılar tarafindan yapılan araştırmaların sayıca azlığı ve Antep Savunmasının yerleşme adları üzerindeki güçlü etkisi, çaIışmanın yapılmasını gerekli kılan etkenlerden birkaçı olarak sıralanabilir.

Ulusal Kurtuluş Savaşı́nın bir parçasını oluşturan Antep Savunmasının toplumun zihninde yer edinmesi nedeniyle günümüzde bile yerleşme adları üzerinde etkisini güçlü bir şekilde sürdürdüğünü yansıtmayı amaçlayan çalışma, Türkiye'de idari birimlere ve yerleşim birimlerine çeşitli unvanlar verilerek mekânın kutsallaştırılması ve vatanın inşa süreci içerisine yerleşme adlarının da dâhil edilmesi nedeniyle, konunun önemini açıklığa kavuşturma gerekliliğine binaen hazırlanmıştır.

Yer ve yerleşme adları üzerine yapılacak coğrafi çalışmalarda, yer verilmesi gereken vazgeçilmez unsurlardan biri haritalardır. Sauer'e (1956) göre haritalar, coğrafyanın dilidir. Coğrafi veriyi depolama, sorgulama, analiz etme ve görselleştirmeye yarayan bir bilgisayar sistemi olan CBS'nin temel işlevlerinden biri mekânların haritalanmasıdır (Wang, vd, 2006). CBS kullanılarak yapılan bilgisayar destekli analizlerdeki mevcut gelişmeler, aynı zamanda, yer ve yerleşme adlarının mekânsal analizindeki imkânları arttırmıştır (Conedera, vd, 2007). Bu çalışmada ise, CBS'den yararlanılarak Antep Savunması'nın yerleşme adları üzerindeki etkisi ve yerleşme adları ile savaş alanları arasındaki ilişki, oluşturulan dağılış ve yoğunluk haritalarıyla yansıtılmaya çalışılmıştır. Çalışmanın temel veri kaynağını, Gaziantep Büyükşehir Belediyesi CBS Şube Müdürlügü'nden sağlanan sayısal veriler oluşturmaktadır. Şahinbey ve Şehitkâmil merkezi ilçelerinin sınırları içerisinde yer alan mahalle ve sokak verilerinden amaca uygun olanlar seçilmiş ve kullanılmıştır. Savaş alanlarına ait konum bilgilerinin belirlenmesinde ise, GPS (Global Positioning System)'den yararlanılmıştır.

\section{Araştırma Sahası}

Kurtuluş Savaşı'nın Güney Cephesi'nin önemli bir kısmını oluşturan Antep Savunması, ağırlıklı olarak Gaziantep şehri ve yakın çevresinde meydana gelmiş çatışmalardan veya olaylardan ibarettir. Kilis, Akçakoyunlu ve Maraş yol güzergâhları boyunca Kuvayi Milliye birliklerinin verdiği mücadeleler ise, şehir savunmasının bir parçasını oluşturmaktaydı (Uzun, 2014). Adını Antep Savunması'ndan alan mahalle ve sokaklar da Gaziantep şehri ve yakın çevresinde bulunmaktadır. Savaş alanları ile adını Antep Savunması'ndan alan yerleşim yerlerinin dağılışı arasındaki alansal yakınlık, araştırma sahasının sınırlarının tespitinde doğrudan belirleyici olmuştur. Araştırma sahası kapsamına ilin tamamı alınırken, Antep Savunması'nın esasında bir şehir savunmasından ibaret olması nedeniyle, özellikle Gaziantep ilinin merkez ilçelerinden ikisini oluşturan Şahinbey ve Şehitkâmil'in 
sınırları içerisinde kalan şehir alanındaki yerleşme adlarına odaklanılmıştır (Şekil 1 ve Şekil 2).

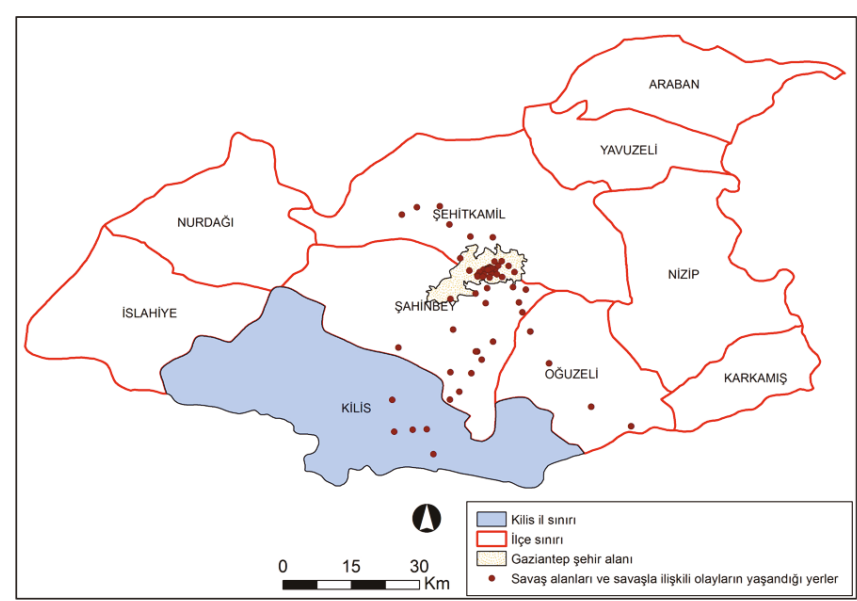

Şekil 1. Savaş alanlarının ve savaşla ilişkili olayların yaşandığı yerlerin dağılışı. Figure 1. Distribution of the battlefields and the areas where the events related to the battle occurred.

Gaziantep, günümüzde konum olarak, Güneydoğu Anadolu Bölgesi sınırları içerisinde ancak Karasal ve Akdeniz iklim bölgeleri arasındaki geçiş kuşağı üzerinde yer almaktadır. Kuzeyde Kahramanmaraş ve Adıyaman, doğuda Şanlıurfa, batıda Osmaniye ve Hatay, güneyde ise Kilis ili ve Suriye devletiyle komşudur (Şekil 2).

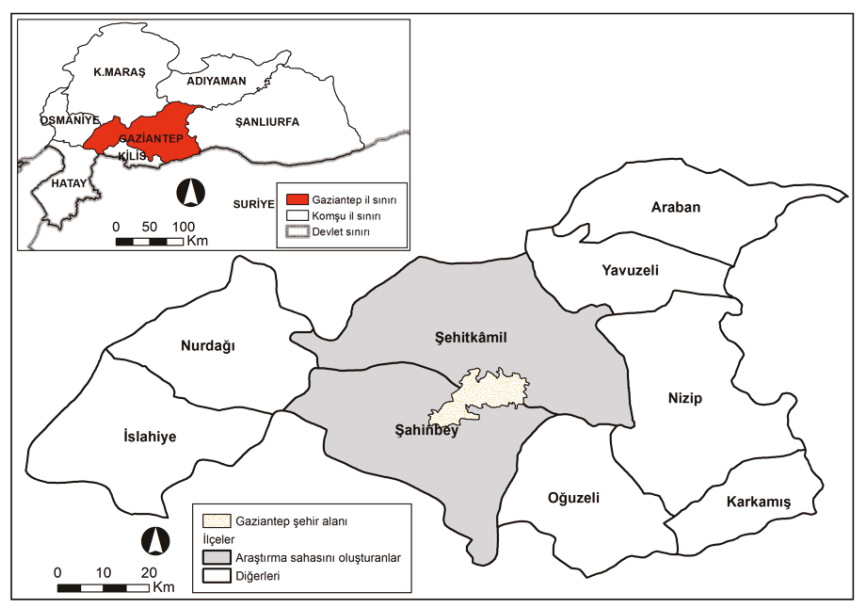

Şekil 2. Araştırma sahası ve yakın çevresinin lokasyon haritası.

Figure 2. Map of the search sector and location of the immediate surroundings.

\section{Bulgular}

Antep, I. Dünya Savaşı'nın ardından 17 Aralık 1918'de İngilizler tarafindan işgal edildi. Daha sonra, 5 Kasım 1919'da, İngilizlerin yerini Fransızlar aldı ve 25 Aralık 1921 tarihine kadar Fransız işgali altında kaldı (Genelkurmay Başkanlığı Harp Tarihi Dairesi, 1966). Bu iki yılı aşkın süre zarfinda, gönüllü yöre halkından oluşan ve başlarında ise onları organize etmeye çalışan asker kökenli subayların bulunduğu Kuvayi Milliye birlikleri tarafindan, Fransızlara karşı büyük bir bağımsızlık mücadelesi verildi. Ulusal
Kurtuluş Savaşımızın bir parçasını oluşturan ve 3 Şubat 1920 ile 8 Şubat 1921 tarihleri arasında gerçekleşen Antep Savunması, dâhil olduğu Güney Cephesi'ndeki mücadelenin en uzun olanı ve en şiddetli süreniydi. Urfa ve Maraş'ta yaşanan çatışmaların süresi iki ayı geçmezken, Antep'te bir yıl kadar devam etti. Şiddeti ve uzunluğu nedeniyle, Antep Savunması süresince çok sayıda çatışma ve olay meydana geldi. Fransızların şehrin çevresindeki tepelerde tam olarak hâkimiyet sağlamasının ardından, şehirde yaşayan Antep halkı aylarca açlığa mahkûm edilerek teslim olmaya zorlandı ve 8 Şubat 1921 tarihinde halk açlığa yenik düştü (Abadi, 1959; Bayaz, 1994; Genelkurmay Başkanlığı Harp Tarihi Dairesi, 1966; Nureddin, 1974; Ünler, 1969; Üzel, 1952). Sonuç olarak Antep Savunması'ndan geriye; Gaziantep ve çevresini içerine alan vatan toprağı, unutulmayacak bir mazi ve gazi bir kent, birçok savaş alanı ve turistik çekiciliğin yanı sıra yerleşme adları kaldı.

\subsection{Antep Savunması'nın Şehir ile il ve İlçe Adları Üzerindeki Etkisi}

Antep Savunması süresince Antep halkının 6317 şehit vermesi ve zor şartlar altında bir yılı aşkın bir süre boyunca Fransızlara karşı büyük bir direniş göstermiş olması nedeniyle TBMM tarafindan 6 Şubat 1921'de şehre "Gazilik" unvanı verilerek şehrin ve ilin Antep olan adı Gaziantep olarak değiştirilmiştir (Bozgeyik, 1998; Dai, 1992; Ünler, 1969).

1987 yılında büyükşehir unvanını elde eden Gaziantep (Çelikyay, 2014), büyükşehir belediyesinin en az üç ilçe veya ilk kademe belediyesini kapsaması gerektiğini belirten Büyükşehir Belediyesi Kanunu'na (23.07.2004 tarih ve 25531 sayılı Resmi Gazete, Kanun No: 5216) uygun olarak Şahinbey, Şehitkâmil ve Oğuzeli ilçelerinden oluşan üç merkez ilçeye ayrılmıştır. 1987'de il merkezinde kurulmuş iki merkez ilçeden biri olan Şahinbey ilçesi, Antep Savunması sürecinde Kuvayi Milliye birliklerini organize eden, Kilis-Antep yolu üzerinde oluşturduğu savunma hatlarıyla Fransızların Antep şehrine girmesine engel olmaya çalışan ve bu uğurda şehit düşen Kuvayi Milliye Komutanı'ndan (Ünler, 1969; Pamuk, 2009) adını almaktadır. Merkez ilçelerden bir diğeri olan Şehitkâmil'e ise, Fransız askerlerine karşı üvey annesini korumaya çalışırken süngülenerek şehit edilen 10-12 yaşlarındaki Kâmil adlı çocuğun adı verilmiştir. İlk bakışta basit gözüken bu olayın büyüklüğü, halkın büyük bir kısmının cenaze törenine katılması ve Ermenilerin işlettikleri haricindeki tüm dükkânlar ile resmi dairelerin protesto amaçlı kapatılması neticesinde cenazenin Fransızlara karşı bir başkaldırı niteliğine dönüşmesinden kaynaklanmaktadır (Bayaz, 1994; Dai, 1992, Nureddin, 1974; Ünler, 1969).

\subsection{Antep Savunması'nın Mahalle Adları Üzerindeki Etkisi}

2012 yılında Büyükşehir Belediyesi Kanunu'nda yapılan değişiklikle birlikte, Gaziantep iline bağlı ilçelerin mülki sınırları içerisinde yer alan köy ve belde belediyelerin tüzel kişiliği kaldırılmış ve böylece köyler mahalle, belediyeler ise belde ismiyle tek mahalle olarak bağıı bulundukları ilçenin belediyesine katılmıştır (06.12.2012 tarih ve 28489 sayılı Resmi Gazete, Kanun No: 6360). Bu nedenle, şehir alanı dışında kalan kırsal yerleşim yerleri de mahalle olarak gösterilmiştir. 
Daha öncede belirtildiği üzere, Antep Savunması'nın ağırlıklı olarak Antep şehri ve yakın çevresinde meydana gelmiş çatşmalardan ve olaylardan ibaret olması nedeniyle özellikle Gaziantep şehir alanındaki yerleşme adlarına odaklanılmıştır. Çalışmanın amacını yerleşme adları-olay-mekân ilişkisinin analiz edilmesi oluşturduğundan Şahinbey, Şehitkâmil haricindeki mahalle yerleşimleri inceleme alanı dışında bırakılmıştır (Şekil 3).

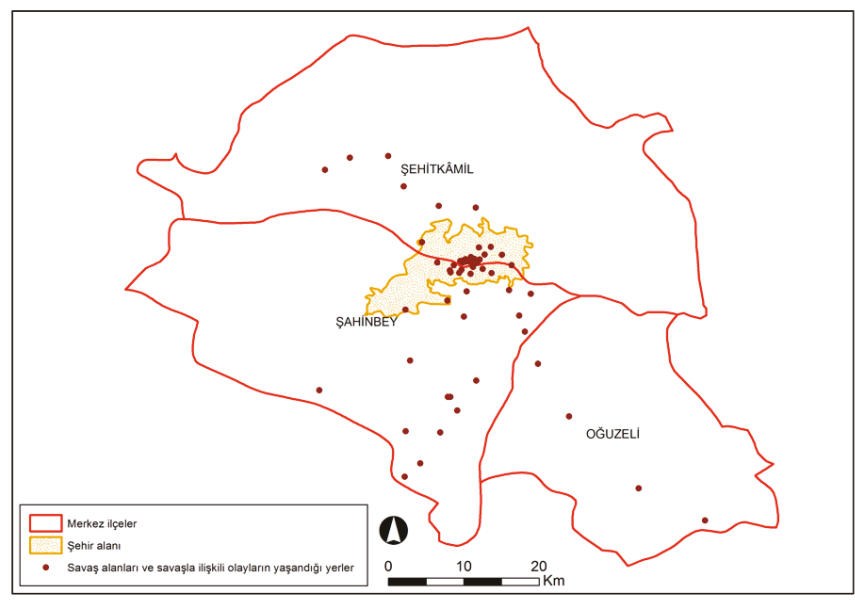

Şekil 3. Savaş alanları ve savaşla ilişkili olayların yaşandığı yerler ile adını Antep Savunması'ndan alan şehir yerleşmesinin ve merkez ilçelerin dağılışı.

Figure 3. Distribution of the battlefields and the areas where the events related to the battle occurred and city settlement and its central districts named after Antep Defence.

Tablo 1'de görüldüğü üzere, adını Antep Savunması'ndan aldığı tespit edilen mahalle sayısı 22'dir. Bu değer, Gaziantep Büyükşehir Belediyesi verilerine göre, Gaziantep il genelindeki toplam 807 mahalle yerleşmesinin yaklaşık \%2,7'sine tekabül etmektedir. Antep Savunması'nın mahalle adları üzerindeki etkisi, ilçelere göre büyük farklılık göstermektedir. Şahinbey ve Şehitkâmil ilçelerinde yer alan mahalleler (Şekil 4), belirtilen 22 mahallenin \% 63'ünü oluşturmakta ve bunun da \% 78'i şehir alanı içerisinde kalmaktadır. Yerleşme yerlerinin dağııışındaki bu sonuç, savaş alanları ve savaşla ilişkili olayların yaşandığı yerlerin dağılışları arasındaki alansal yakınlığı göstermektedir.

Tablo 1. Adını Antep Savunması'ndan alan mahallelerin, miktar olarak, ilçelere göre dağılımı.

Table 1. Distribution of the number of the quarters named after Antep Defence according to the districts.

Mahalle Sayısı

\begin{tabular}{c|c|c|c|c|c|c|c|c}
\hline İslahiye & Nurdağı & Şahinbey & Şehitkâmil & Oğuzeli & Nizip & Araban & Yavuzeli & Karkamış \\
\hline 2 & 1 & 8 & 6 & 2 & 3 & - & - & - \\
\hline
\end{tabular}

Kaynak: Gaziantep Büyükşehir Belediyesi verilerinden derlenmiştir.

Kurtuluş, Şahinbey, İstiklal, Gazi sıklıkla tekrarlanan mahalle adlarını oluştururken, Antep Savunması'nda kahramanlıklarıyla ön plana çıkan şehit ve gazilerin adlarına yani kişi adlarına da fazlaca yer verilmiştir. Örneğin Özdemirbey Mahallesi, şehir içindeki savaşı yürüten Kuvayı Milliye birliklerini organize eden komutandan (Ünler, 1969); Boynoköy ve Boyno mahalleleri, Kertil ve Elmalı-Bostancık savunma hatları ile Dülükbaba'da Fransızlara karşı savaşan ve Antep Savunması sonrasında İstiklal Madalyası'yla onurlandırılan milis kuvvetler komutanından
(Uzun, 2014); Karayılan Mahallesi ise, Kuvayı Milliye birlikleri ile birlikte Akçakoyunlu İstasyonu, Sarımsaktepe ve Çınarlı Cephesi'nde Fransızlara karşı savaşmış mahalli kahramandan (Ünler, 1969; Nureddin, 1974) adını almaktadır.

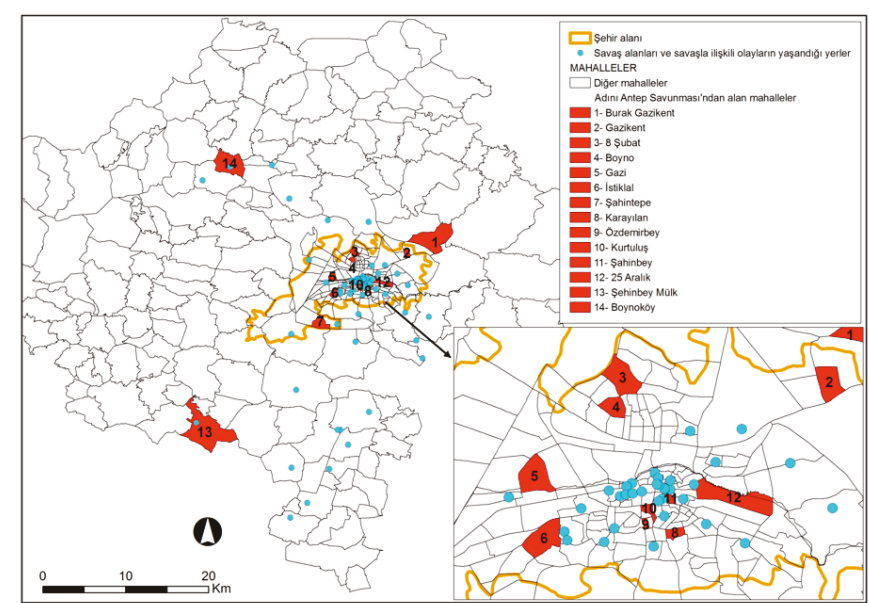

Şekil 4. Adını Antep Savunması'ndan alan mahalleler ile savaş alanları ve savaşla ilişkili olayların yaşandığı yerlerin Gaziantep şehri ve yakın çevresindeki dağılımı (Gaziantep Büyükşehir Belediyesi CBS Şube Müdürlüğü'nden 2016 yıIında alınan sayısal verilerden oluşturulmuştur).

Figure 4. The distribution of the quarters named after Antep Defence and the battlefields and the areas where the events related to the battle occurred in Gaziantep and immediate surroundings (Compiled according to the numerical data obtained from the CBS Branch Office of Gaziantep Metropolitan Municipality in 2016).

\subsection{Antep Savunması'nın Sokak Adları Üzerindeki Etkisi}

Cadde ve bulvar ile sokak arasındaki ayırım iki sebepten dolayı çalışmada dikkate alınmamış, bütün veriler sokak adı altında sınıflandırılmıştır. Sokak ile cadde ve bulvar arasındaki farklılıklar bu çalışmada önem arz etmediği gibi, adres ve numaralamaya ilişkin yönetmeliğe (31.07.2006 tarih ve 26245sayılı Resmi Gazete'de yayımlanan) bakıldığında; bulvarın yerleşim yeri içindeki geniş cadde, caddenin ise yerleşim yeri içindeki geniş ve uzunca sokak olarak tanımlanması, bu iki kavramın temel dayanağının sokak olduğunu göstermektedir.

Araştırma sahasını oluşturan Şahinbey ve Şehitkâmil ilçelerinde, adını Antep Savunması'ndan aldığı tespit edilen sokak sayısı 28 'dir. Bu sayı, ilçelerin 11 bini aşan toplam sokak sayısının \% 0,25'ine tekabül etmektedir. Sokak adlarının büyük çoğunluğunu; Şahinbey, Özdemirbey, Şehitkâmil, Kılıç Ali, Karayılan, Dayı Ahmet Ağa, Lohanlızade Mustafa Nureddin, Tüfekçi Yusuf, Ali Nadi Ünler gibi Antep Savunması'nda kahramanlıkları ve hizmetleriyle ön plana çıkmış şehit ve gazilerin adları oluşturmaktadır. Antep Savunması süresince şehit verilen 6 bini aşkın isimsiz kişinin adı ise, Adsız Kahramanlar ve Adsız Şehitler adı altında sokak adlarına verilmiştir.

Mahalle adlarında olduğu gibi, araştırma konusuyla ilişkili sokak adlarına en fazla şehir yerleşim alanında rastlanmaktadır. Adını Antep Savunması'ndan alan sokakların bulunduğu mahallelerden Durantaş ve Aktoprak mahalleleri şehir alanı dışında kalırken, diğerleri kısmen veya tamamen şehir alanı içerisinde yer almaktadır (Şekil 5). 


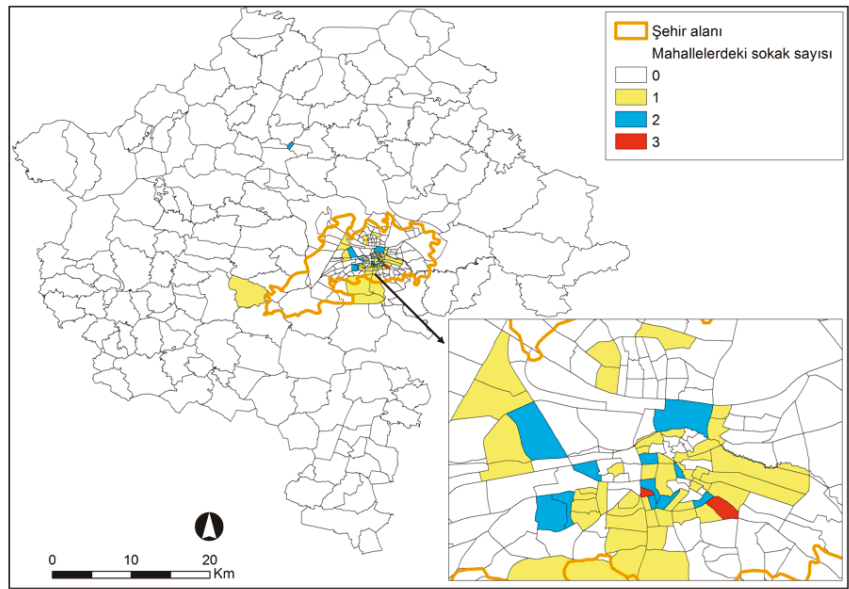

Şekil 5. Adını Antep Savunması́ndan alan sokakların, miktar olarak, mahalle bazındaki dağılımı (Gaziantep Büyükşehir Belediyesi CBS Şube Müdürlüğü'nden 2016 yılında alınan sayısal verilerden oluşturulmuştur).

Figure 5. Distribution of number of streets named after Antep Defence on the basis of quarters (Compiled according to the numerical data obtained from the CBS Branch Office of Gaziantep Metropolitan Municipality in 2016).

\section{Sonuç}

Antep Savunması süresince 6317 şehit verilmesi ve zor şartlar altında bir yılı aşkın bir süre boyunca Fransızlara karşı büyük bir direniş gösterilmiş olması nedeniyle TBMM tarafindan 6 Şubat 1921 'de şehre "Gazilik" unvanı verilerek Antep halkının onurlandırılması, Türklerin eski inanç ve törelerindeki ad verme geleneğiyle benzeşmekte ve yerleşme adlarının, vatanın inşa süreci olarak görüldüğünün bir göstergesidir.

Antep Savunması'nın yerleşme adları üzerindeki etkisinin Coğrafi Bilgi Sistemleri aracılığıyla analiz edildiği bu çalışmada;

-Antep Savunması'ndan geriye, Gaziantep ve çevresini kapsayan vatan toprağı, unutulmayacak bir mazi ve gazi bir kent, birçok savaş alanı ve turistik çekiciliğin yanı sıra yerleşme adlarının kaldığı,

-ilin, şehrin ve iki merkez ilçenin, mahalle yerleşmelerinin \% 2,7'sinin, Gaziantep şehrindeki sokak sayısının \% 0,25'inin adı üzerinde Antep Savunması'nın etkisinin görüldüğü,

-Kurtuluş, Şahinbey, İstiklal, Gazi gibi mahalle adlarının farklı ilçelerde sıklıkla kullanıldığı,

-Sokak adlarında, Antep Savunması'nda kahramanlıklarıyla ön plana çıkan şehit ve gazi adlarına yani kişi adlarına fazlaca yer verildiği,

-Adını Antep Savunması'ndan alan mahalle ve sokakların dağııışı ile savaş alanları ve savaşla ilişkili olayların yaşandığı yerlerin dağılışlarının büyük oranda birbiriyle örtüştüğü,

-Savaşın ağırlık merkezinin Antep şehri olması nedeniyle, Antep Savunması'nın yerleşme adları üzerindeki etkisinin Şahinbey ile Şehitkâmil merkez ilçelerinde daha belirgin olarak gözüktüğü,

tespit edilmiştir.

Sonuç olarak, TBMM tarafindan 6 Şubat 1921'de şehre "Gazilik" unvanı verilerek başlayan adlandırma süreci, Antep Savunması'nda önemli yere sahip kişi veya olaylara günümüzde mahalle ve sokak adlarında yer verilmesiyle devam etmektedir. Bu durum, ulus devlet politikasının yerel ve ulusal düzeyde uy- gulandığını gösteren kanıtlardan biri olarak belirtilebilir. Ayrıca, Antep Savunması'nın toplum zihnindeki tazeliğini ve yerini koruduğunun da göstergesidir. Olayın toplum zihinde yer edinmesi ve mekân adlandırılmasında kullanılması, toplumsal belleğin oluşumuna katkı sağladığı gibi gelecek nesillere aktarılmasına da olanak sağlar.

\section{Kaynakça}

Abadi, M. (1959). Türk Verdünü Gaziantep, (A.N. Ünler \& Ş.S. Yener, \& Ö.A. Aksoy, Çev.). Gaziantep: Gaziantep Kültür Derneği Kitap ve Broşür Yayınları, Gaziantep.

Alagöz, C. A. (1984). Türkiye Yer Adları Üzerine Bazı Düşünceler. Türk Yer Adları Sempozyumu 1984-Coğrafya-Bildiri: 11-23, Ankara.

Ayanovna, N. L. (2014). The Role of Old Turkic Place Names in Teaching History. Procedia Social and Behavioral Sciences 141: 1054-1061.

Bayaz. H. (1994). Antep Savunması Günlügüu. İstanbul: Cem Yayınevi, İstanbul.

Bozgeyik, B. (1998). İstiklal Harbinde Gaziantep (3. Baskı). Gaziantep: Gaziantep Şehitkâmil Belediyesi Kültür Müdürlüğü Yayınları, Gaziantep.

Conedera, M., Vassere, S., Neff, C., Meurer, M. and Krebs, P. (2007). Using Toponymy to Reconstruct Past Land Use: A Case Study of Brüsada (Burn) in Southern Switzerland. Journal of Historical Geography 33 (4): 729-748.

Çelikyay, H. (2014). Değişen Kent Yönetimi ve 6360 Sayılı Büyükşehir Yasası. http://file.setav.org/Files/Pdf/20140708140310_degisenkent-yonetimi-ve-6360-sayili-buyuksehir-yasasi-pdf.pdf. Son erişim 08 Ekim 2018.

Dai, A. (1992). Olaylarla Gaziantep Savaşı. Gaziantep: Gaziyurt Matbaası Basımı, Gaziantep.

Durgun, S. (2018). Memalik-i Şahane'den Vatan'a. İstanbul: Iletişim Yayınları, İstanbul.

Gaziantep Büyükşehir Belediyesi CBS Şube Müdürlüğü.(2016). Mahalle ve sokak verileri.

Giraut, F. \& Holzschuch, M. H. (2016). Place Naming as Dispositif: Towards A Theoretical Framework. Geopolitics 21: 1-21.

Khvesko, T. V. (2014). Interdisciplinary Approach to British Place Names Studies. Procedia-Social and Behavioral Sciences 154: 402406.

Işıkhan, T. (2008). Gaziantep Yer Adlarının Halkbilimi Bakımından Değerlendirilmesi (Yayımlanmamış Yüksek Lisans Tezi). Gazi Üniversitesi Sosyal Bilimler Enstitüsü. Ankara.

İnan, A. (1976). Eski Türk Dini Tarihi (Kültür Bakanlığı Eserleri: 9). İstanbul: Milli Eğitim Basımevi, İstanbul.

Nureddin, L. M. (1974). Gaziantep Müdafaası. Gaziantep: Gaziantep Kültür Derneği Kitap ve Broşür Yayınları, Gaziantep.

Pamuk, B. (2009). Bir Şehrin Direnişi: Antep Savunması. İstanbul: IQ Kültür ve Sanat Yayıncılık, İstanbul.

T.C. Genelkurmay Başkanlı̆̆ Harp Tarihi Dairesi. (1966). Türk Istiklal Harbi (TiH) Güney Cephesi (IV. Cilt). Ankara: Genelkurmay Başkanlığı Harp Tarihi Dairesi Resmi Yayınları, Ankara.

T.C. İçişleri Bakanlığı iller İdaresi Genel Müdürlüğü. (1977). Yeni Tabii Yer Adları 1977. Ankara: IIller İdaresi Genel Müdürlüğü Yayınları, Ankara.

T.C. Resmi Gazete, Büyükşehir Belediyesi Kanunu.

http://www.resmigazete.gov.tr/eskiler/2004/07/20040723.htm\#1. Son erişim 10 Ekim 2018.

T.C. Resmi Gazete, Adres ve Numaralamaya ilişkin Yönetmelik.

http://www.resmigazete.gov.tr/eskiler/2006/07/20060731-1.htm. Son erişim 10 Ekim 2018

T.C. Resmi Gazete, On Üç İlde Büyükşsehir Belediyesi Ve Yirmi Alt İlçe Kurulması İle Bazı Kanun ve Kanun Hükmünde Kararnamelerde Değişiklik yapılmasına Dair Kanun.

http://www.resmigazete.gov.tr/eskiler/2012/12/20121206-1.htm. Son erişim 10 Ekim 2018. 
Sauer, C.O. (1956). The Education of A Geographer. Annals of Association of American Geographers 46 (3): 287-299.

Sönmez, M.E. (2012). Yerleşme Yeri Seçimi ve Alansal Gelişimi Açısından Gaziantep. Malatya: Özserhat Yayıncılık, Malatya.

Tunçel, H. (2000). Türkiye'de İsmi Değiştirilen Köyler. Fırat Üniversitesi Sosyal Bilimler Dergisi 10 (2): 23-34.

Uzun, E. (2014). Savaş Alanları Turizmi Üzerine Coğrafi Bir Değerlendirme: Antep Savunması Örneği (Yayımlanmamış Doktora Tezi). Atatürk Üniversitesi Sosyal Bilimler Enstitüsü. Erzurum.

Ünler, A. N. (1969). Türk'ün Kurtuluş Savaşı'nda Gaziantep Savunması. İstanbul: Kardeşler Matbaacılık, ìstanbul.

Üzel, S. (1952). Gaziantep Savaşının iç̧ Yüzü. Ankara: Doğuş Ltd. O. Matbaası Basımı, Ankara.

Wang, F., Hartmann, J., Luo, W., Huang, P. (2006). GIS Based Spatial Analysis of Tai place names in Southern China: An Exploratory Study of Methodology. Geographic Information Sciences 12: 1-8. 